\title{
Chromosomal Abnormalities and Hormonal Imbalance in Patients with Amenorrhea in Tamilnadu
}

\author{
G Bhavani $^{1 *}$, RS Chandra', D Anuradha ${ }^{2}$, ST Santhiya ${ }^{1}$ \\ From International Conference on Human Genetics and 39th Annual Meeting of the Indian Society of \\ Human Genetics (ISHG) \\ Ahmadabad, India. 23-25 January 2013
}

\section{Background}

Amenorrhea is the absence of menstrual bleeding in women of reproductive age. Multifarious causes such as pregnancy, absence of uterus and vagina, hormonal imbalance, excess of male testosterone, endometritis and improper functioning of ovaries could be attributed. It is the sixth major cause of female infertility. The present study was undertaken to determine the prevalence of chromosomal anomalies in patients with amenorrhea and to correlate the karyotype with the clinical condition.

\section{Materials \& Methods}

The study comprised of cases with provisional diagnosis of Primary Amenorrhea [ $n=74]$, Secondary Amenorrhea $[n=13]$, Turner Syndrome [ $n=8]$, Gonadal dysgenesis $[n=4]$ and a case of Androgen insensitivity syndrome.

\section{Results}

In the present study, Eighty-one cases revealed normal karyotype $(46, \mathrm{XX})$ while, the remaining 19 cases showed abnormal chromosomal pattern. The most frequent abnormal karyotype in these patients was of 46,XY females [n=6] followed by 45,X [n=5]. Two individuals showed $45, \mathrm{X} / 46, \mathrm{X}, \mathrm{i}(\mathrm{X})(\mathrm{q} 10)$ and a single case each of 45,X/46,XX; 45,X/46,XY; 45,X/46,X,r(X); 46,X,i(Xq); 46, $\mathrm{X}, \operatorname{del}(\mathrm{X})(\mathrm{q} 21.2)$ and $46, \mathrm{X}, \operatorname{del}(\mathrm{X})(\mathrm{p} 11)$ respectively were also observed. The percentage of chromosomal abnormalities in patients with PA and SA were $18 \%$ and $7.6 \%$ respectively. Hormonal profiling wherever possible revealed an elevated level of FSH in 47 individuals
[52.8\%] and that of LH in 34 [43.2\%] of them. Altered levels of other hormones such as PRL [3.09\%], T3 [11\%], T4 [9\%] and TSH [12\%] were seen. Most of the patients had hormone values appropriate to the postmenopausal range. Detailed molecular analysis of possible candidate genes in cases of $46, \mathrm{XY}$ females has been proposed to resolve genetic etiology.

\section{Conclusion}

This study has shown the spectrum of chromosomal abnormalities underlying amenorrhea.

\section{Authors' details}

${ }^{1}$ Dr ALM Post Graduate Institute of Basic Medical Sciences, University of Madras, Taramani, Chennai-600113, India. ²Department of Medical Genetics, Institute of Obstetrics and Gynecology, Madras Medical College, Government Hospital for Women and Children, Egmore, Chennai-600008, India.

Published: 21 January 2014

\section{doi:10.1186/1755-8166-7-S1-P46}

Cite this article as: Bhavani et al:: Chromosomal Abnormalities and Hormonal Imbalance in Patients with Amenorrhea in Tamilnadu. Molecular Cytogenetics 2014 7(Suppl 1):P46.

\footnotetext{
* Correspondence: Bhavani.sekaran@gmail.com

'Dr ALM Post Graduate Institute of Basic Medical Sciences, University of

Madras, Taramani, Chennai-600113, India

Full list of author information is available at the end of the article
} 